\title{
STUDY OF ANATOMICAL PATTERN OF LUMBAR PLEXUS IN HUMAN (CADAVERIC STUDY)
}

\section{BY}

\author{
Prof. Gamal S Desouki, prof. Maged S Alansary,dr Ahmed K Elbana and Mohammad H \\ Mandor
}

\section{FROM}

Professor Anatomy and Embryology Faculty of Medicine - Al-Azhar University

professor of anesthesia Faculty of Medicine - Al-Azhar University

Anatomy and Embryology Faculty of Medicine - Al-Azhar University

Department of Anatomy and Embryology Faculty of Medicine of Al-Azhar University, Cairo

\begin{abstract}
The lumbar plexus is situated within the substance of the posterior part of psoas major muscle. It is formed by the ventral rami of the frist three nerves and greater part of the fourth lumbar nerve with or without a contribution from the ventral ramus of last thoracic nerve. The pattern of formation of lumbar plexus is altered if the plexus is prefixed (if the third lumbar is the lowest nerve which enters the lumbar plexus) or postfixed (if there is contribution from the $5^{\text {th }}$ lumbar nerve). The branches of the lumbar plexus may be injured during lumbar plexus block and certain surgical procedures, particularly in the lower abdominal region (appendectomy, inguinal hernia repair, iliac crest bone graft harvesting and gynecologic procedures through transverse incisions). Thus, a better knowledge of the regional anatomy and its variations is essential for preventing the lesions of the branches of the lumbar plexus.
\end{abstract}

Key Words: Anatomical variations, Lumbar plexus.

\section{Introduction}

The lumbar plexus formed by the ventral rami of the upper three nerves and most of the fourth lumbar nerve with or without a contribution from the ventral ramous of last thoracic nerve. It is located within the substance of the posterior part of psoas major muscle in front of transeverse processes of lumber vertebrae (Standring and Borley, 2008). Branches of the lumbar plexus include, iliohypogastric nerve which arises from the (L1), ilioinguinal nerve (L1), lateral femoral cutaneous nerve (LFCN) which arise from the (L2,3) and femoral nerve which arise from dorsal division of ventral rami of $(\mathrm{L} 2,3,4)$ appear in that order from above downward, at the lateral border of the psoas major muscle while the genitofemoral nerve (GFN) which arises from $(\mathrm{L} 1,2)$ appears on the anterior surface and the obturator nerve which arises from ventral 
division of ventral rami of $(\mathrm{L} 2,3,4)$ emerges along the medial border of the psoas major muscle. The same is the position of accessory obturator nerve $(\mathrm{L} 3,4)$ as it is present in about 29\% of cases (Anloague et al., 2010).

\section{Material and methods}

Twenty lumbar plexuses in ten adult human cadavers obtained from anatomy department faculty of medicine Al-Azhar University preserved in formalin are used and dissected bilaterally. The two sides of the abdominal cavity dissected to compare the morphology of the two psoas major muscles and lumbar plexuses in each cadaver. All preserved cadavers have a normal anatomy and free from any spinal or retroperitoneal pathology with no signs of surgery, wound scars or trauma in the abdomen. $10 \mathrm{ml}$ of dye (methylene blue) injected, the trocar needle removed and the cannula secured to the skin.

Needles;22-gauge, 10 -cm long needle were used for the majority of cadavers. $15-\mathrm{cm}$ needles may be needed for obese cadavers. 18-gauge, 10-cm Tuohy needle was used for catheter placement. Catheters introduced $5 \mathrm{~cm}$ beyond needle tip.

\section{Methods}

According to Capdevila's approachthe cadaver was placed in the lateral position. The puncture point is at the junction of the lateral one third and medial two thirds of the line joining L4 to the line passing through the posterior superior iliac spine (PSIS) (fig. 1) (Capdevila et al., 2005).

After needle insertion, a $10 \mathrm{~cm}$ syringe was used to inject $10 \mathrm{~cm}$ methylene blue dye. Following injection, the peritoneum was removed to expose the psoas major (anterior approach). The branches were identified as they pierce the anterior, medial and lateral borders of the psoas major muscle. The extent of spread of methylene blue dye was documented by photography at each stage of the dissection. Both sides of the abdominal cavity were dissected to compare the morphology of the lumbar plexuses. The muscles of the posterior abdominal wall exposed. While doing so, injury to the vessels and nerves related to the muscles was avoided. The psoas major muscle was detached from the intervertebral discs and vertebral bodies. The nerves and their branches will be traced till their exit at the intervertebral foramina

The nerves of the lumbar plexus were traced from the lumbar roots to their exit from the pelvic cavity. The results were described narratively with descriptive statistics and recorded with digital photography. The lumbar nerves which constitute the plexus were measured using anatomical landmarks and the data recorded. The measurements were made with the help of the thread and ruler with markings in millimeters. The thickness and the length of each lumbar nerve were measured separately.All the formations of the lumbar plexus were photographed. The observations so made were recorded and compared with standard texts as well as with accessible literature (Gandhi et al., 2013). 


\section{Results}

The injectate (methylene blue) spread within the psoas muscle along the fascial plane between the psoas major and quadratus lumborum muscles (fig. 2). At the level of the fifth lumbar vertebra, the dye surrounded the femoral and obturator nerves. Additionally, there was evidence of cranial spread of the injectate by expansion of the intrapsoas fascia. The lumbar plexus originated from the ventral rami of the first four lumbar roots (fig. 3) and lied within and/or around the psoas major. It occasionally received a thin branch from the 12th thoracic root. The plexus had a triangular form and lied from the upper part of lumbar region to the pelvis. The main six nerves originated from the lumbar plexus were observed; iliohypogastric nerve, ilioinguinal nerve, genitofemoral nerve, lateral femoral cutaneous nerve, obturator nerve and femoral nerve arranged from above downwards (fig. 4).

Lumbar plexus lies between: (a) the fleshy slips of the main part of the psoas major that arise from the anterolateral part of the vertebral bodies of the last thoracic and all lumbar vertebrae and the intervertebral disc and (b) the accessory part of the psoas, posterior to the main part of the muscle, that originated from the front and lower border of the transverse processes. The two parts of the muscle fused to form the psoas major. The first lumbar ventral ramus divided to give the iliohypogastric and ilioinguinal nerves that leave the psoas muscle to travel anteriorly to the quadratus lumborum (fig. 5). The genitofemoral and the lateral femoral cutaneous nerves originate from the second lumbar ventral ramus (fig. 6). The first descends on the ventral aspect of the psoas major muscle while the latter crosses the lateral border of the psoas major at the level of the inferior margin of the fourth lumbar vertebra (fig. 7).

The large dorsal divisions of the ventral rami of L2, 3, 4 united to form the femoral nerve. It was medial to the lateral femoral cutaneous nerve (fig. 8). The femoral nerve left the psoas major from its postero-lateral border at the junction of the muscle's upper two thirds and lower third. It then traveled in the gutter between the psoas major and iliacus muscles deep to fascia iliaca.

The ventral divisions of L2, 3, 4 united to form the obturator nerve. The obturator nerve, being medial to the femoral nerve, was the innermost nerve of the lumbar plexus. The obturator nerve left the psoas muscle on its internal and posterior side between L5 and SI (fig. 8). The iliohypogastric nerve was the longest lumbar nerve in the posterior abdominal region according to selected landmarks shown in (Table I). The mean length of the iliohypogastric nerve was $210 \mathrm{~mm}$ (range: 207-213 mm), while the shortest lumbar nerve in our study was the femoral nerve at $154 \mathrm{~mm}$ (range: 152$156 \mathrm{~mm}$ ) (fig. 9, 10).

In the present study, the lumber plexus was located in the posterior one third of the psoas major muscle. Most frequent variations were found in GF nerve. Sexual dimorphism was not considered because of small sample size of female cadavers. No significant difference was found comparing the sides of the cadavers.

The genitofemoral nerve (GF) was originating from the ventral ramus of L2. A second branch which was also originated from the ventral ramus of L2 was coursing 
parallel to this nerve. The genital ramus was entering the deep inguinal ring. It is mostly accessory genital nerve (Fig. 12, 13).

The lateral femoral cutaneous nerve is normally a branch of the lumbar plexus. We found the origin of lateral cutaneous nerve of thigh from the femoral nerve in two lumbar plexuses (Fig. 14). We found high division of the femoral nerve in two lumbar plexuses. In a right lumbar plexus of a male cadaver, the femoral nerve divided in iliac fossa $40 \mathrm{~mm}$ above the inguinal ligament into anterior and posterior divisions. The nerve to pectineus arose from the anterior division of the femoral nerve (Fig. 15).

The GF nerve pierced the middle third of psoas major at the L3-4 vertebral level, in $18(90 \%)$ out of 20 lumbar plexuses, whereas in the rest, it pierced the upper third of the muscle. The nerve was observed as a single stem in $18(90 \%)$ of cadavers at its emergence from the psoas major. This single stem divided into genital and femoral branches at a mean distance of $5.5 \mathrm{~cm}$ above the inguinal ligament (IL). In 2 (10\%) cases, GF bifurcated into the genital and femoral branches at the upper rather than midportion of the anterior surface of the psoas. The femoral branch lying medial to the genital nerve (Fig. 16). Typically, the genitofemoral nerve bifurcates into its terminal genital and femoral branches midway along the anterior surface of the psoas major.

\begin{tabular}{|c|c|c|}
\hline Nerve & Length landmarks & Mean length (Range) \\
\hline Iliohypogastric nerve & $\begin{array}{c}\text { Dividing point to the anterior } \\
\text { and lateral cutaneous branches }\end{array}$ & $210 \mathrm{~mm}(207-213 \mathrm{~mm})$ \\
\hline Ilioinguinal nerve & $\begin{array}{c}\text { The entrance point to the } \\
\text { inguinal canal }\end{array}$ & $188 \mathrm{~mm}(185-190 \mathrm{~mm})$ \\
\hline Genitofemoral nerve & $\begin{array}{c}\text { Dividing point to the } \\
\text { genital and femoral branches }\end{array}$ & $164 \mathrm{~mm}(162-167 \mathrm{~mm})$ \\
\hline $\begin{array}{c}\text { Lateral femoral } \\
\text { cutaneous nerve }\end{array}$ & $\begin{array}{c}\text { belowt where it passes } \\
\text { The entrance point to the } \\
\text { obturator foramen }\end{array}$ & $186 \mathrm{~mm}(184-189 \mathrm{~mm})$ \\
\hline Obturator nerve & $\begin{array}{c}\text { The point where it passes } \\
\text { below the inguinal ligament }\end{array}$ & $154 \mathrm{~mm}(152-156 \mathrm{~mm})$ \\
\hline Femoral nerve & \multicolumn{2}{|c|}{$\mid$} \\
\hline
\end{tabular}

ATable showing The length of branches of the lumbar plexus in the posterior abdominal region after complete exposure of the lumbar plexus. 


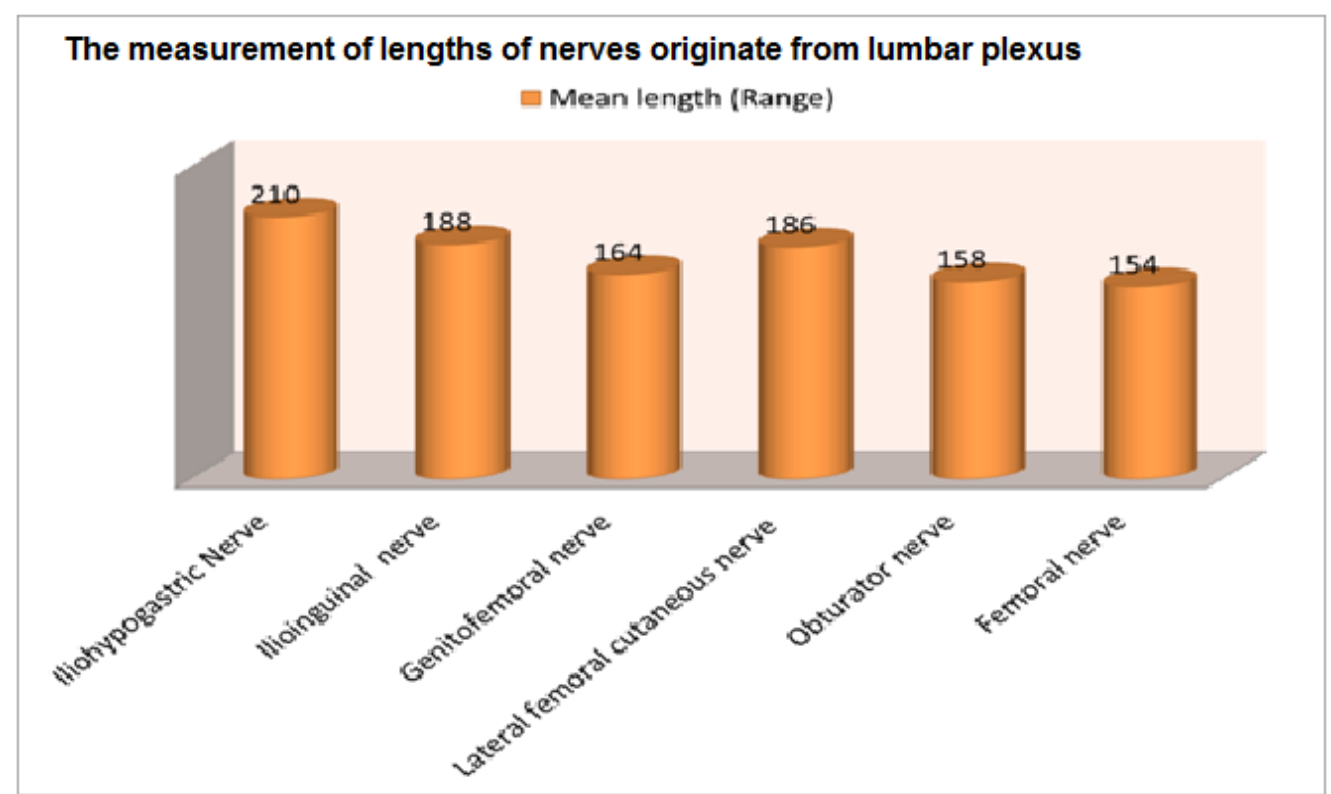

Histogram showing the measurement of lengths of nerves originate from lumbar plexus in millimeters $(\mathrm{mm})$. The iliohypogastric nerve was the longest lumbar plexus nerve while the shortest lumbar nerve in our study was the femoral nerve.

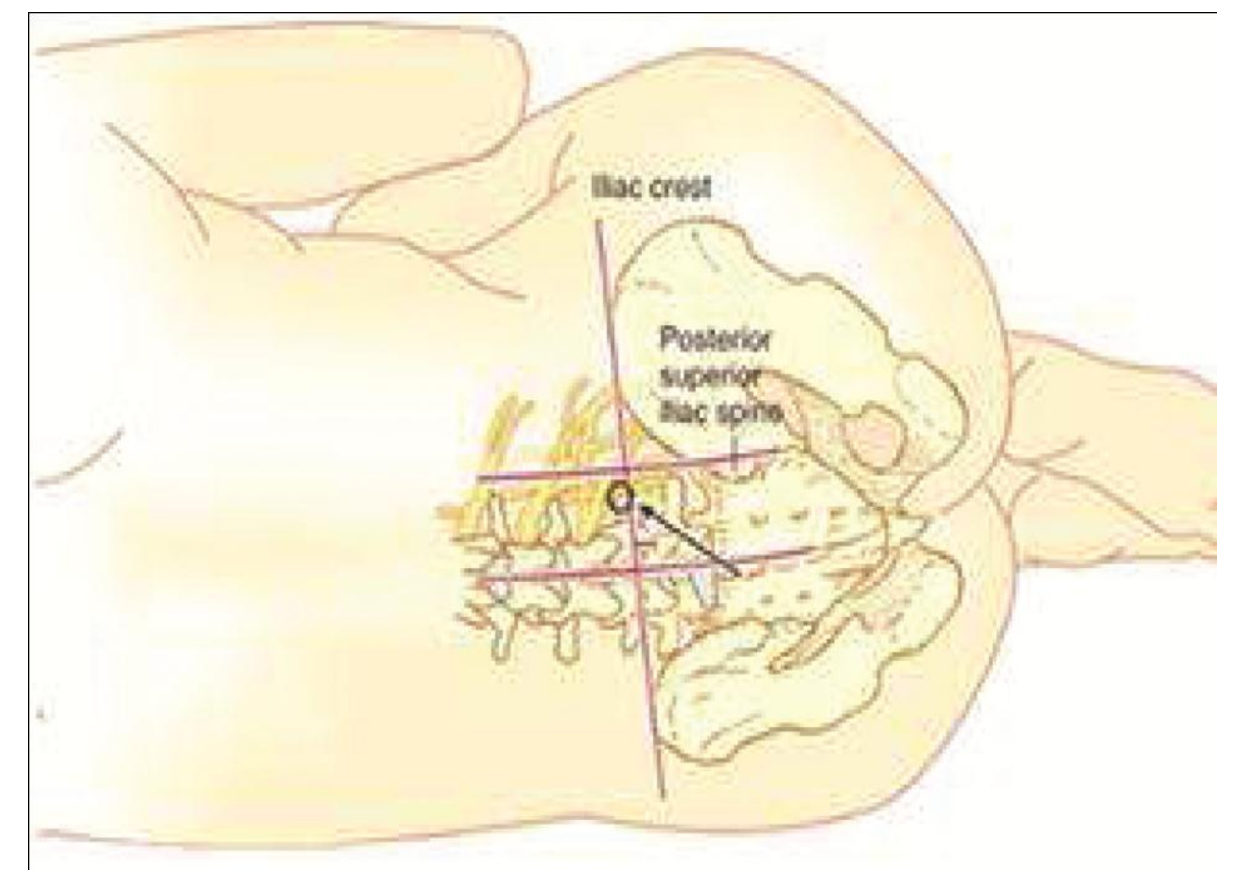

Fig. (1): showing the spinous process of L4. A line is drawn from the centre of the L4 spinous process laterally, to intersect with a line that passes through the posterior superior iliac spine parallel to the vertebral column on the side to be blocked. The puncture point is at the junction of the lateral one third and medial two thirds of the line joining L4 to the line passing through the PSIS (Capdevila et al., 2005). 


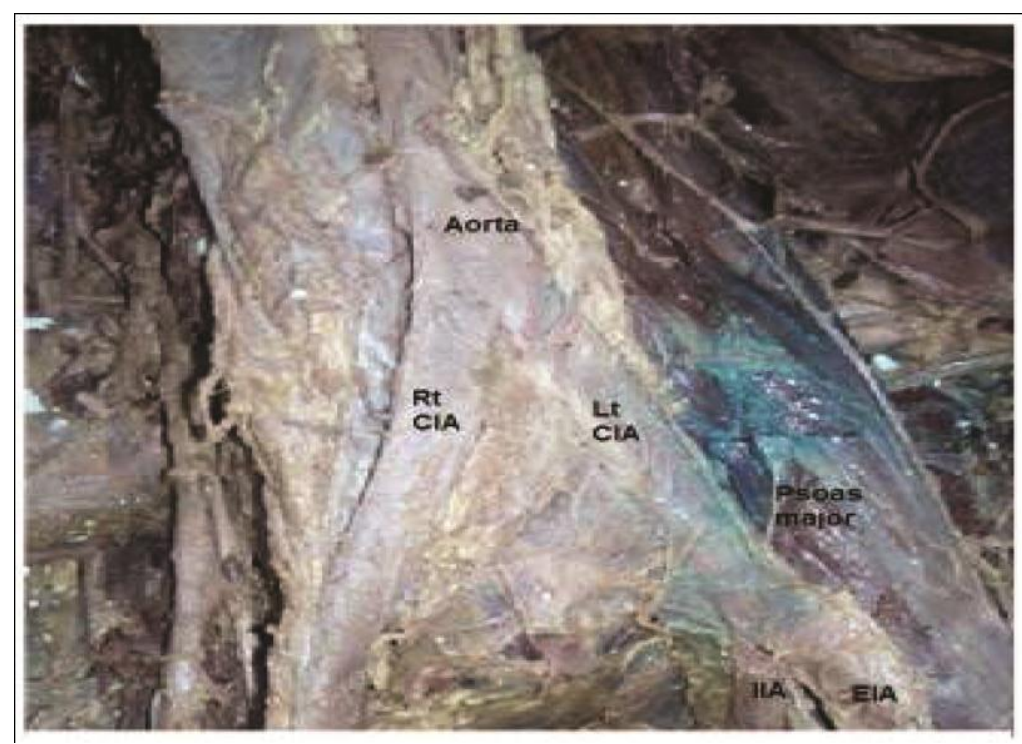

Fig. (2): Aphotograph showing the injectate (methylene blue) spread within the left psoas muscle Rt CIA = right common iliac artery, Lt CIA= left common iliac artery, $\mathrm{IIA}=$ internal iliac artery and EIA= external iliac artery.
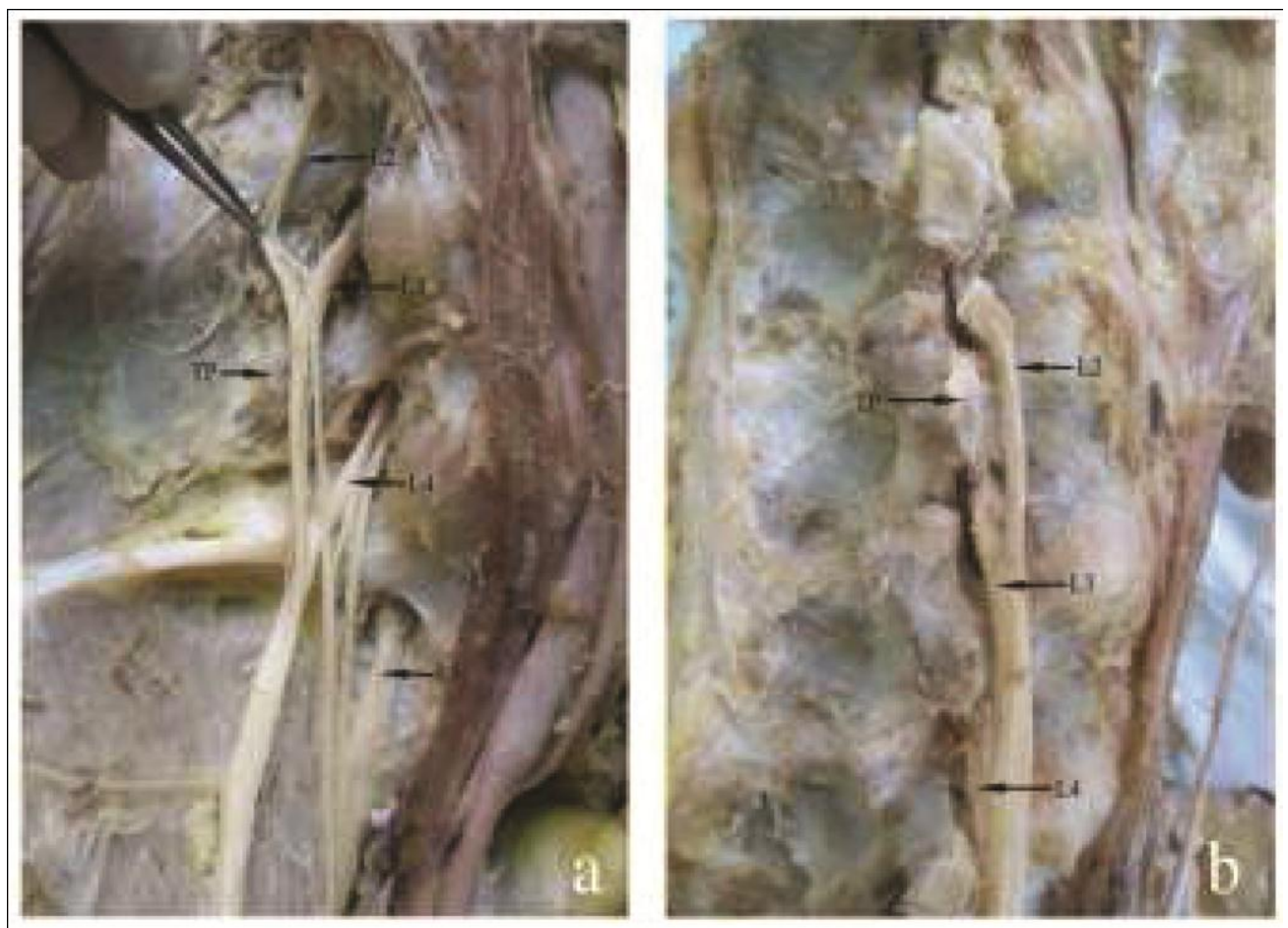

Fig. (3): Aphotograph showing arrangement of the lumbar nerves. (a) anterior view; (b) lateral view, ventral rami of lumbar nerves from L2 to L5. Transverse process (TP). 


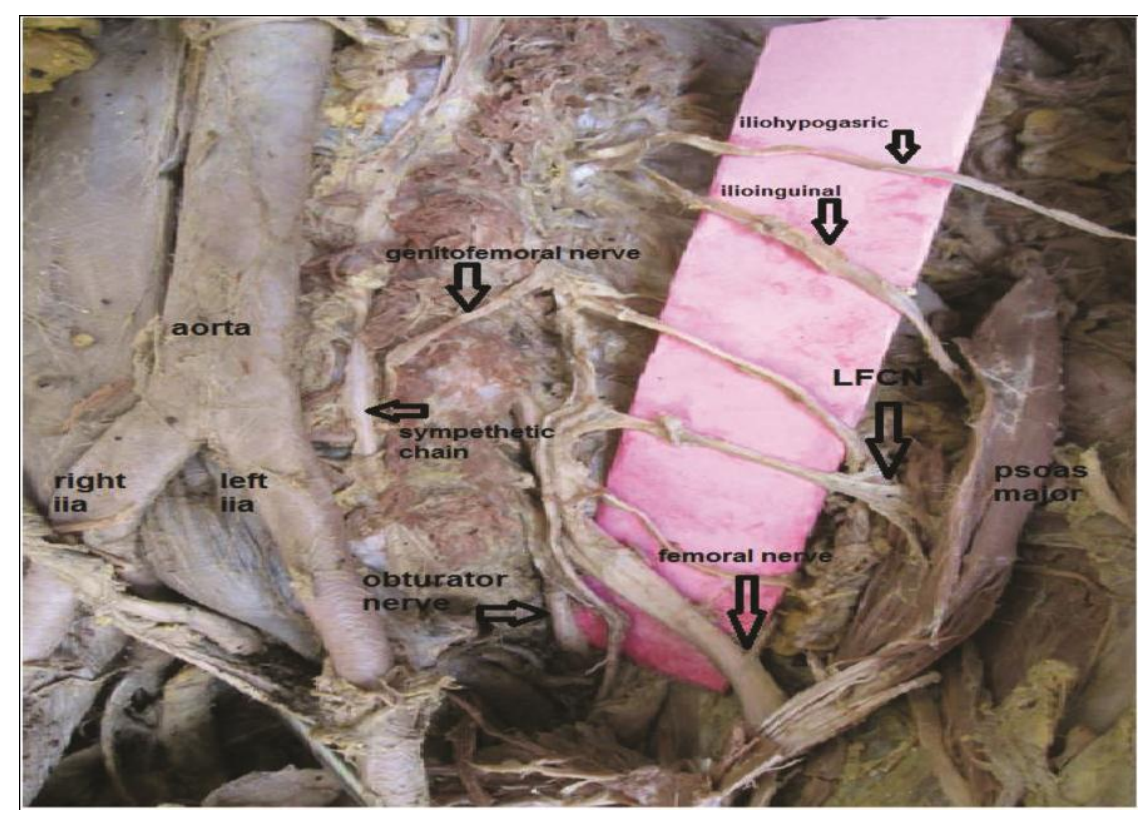

Fig. (4): Aphotograph showing the entire lumbar plexus on the left side after removal of quadratus lumborum and psoas major muscles (Normal anatomy).

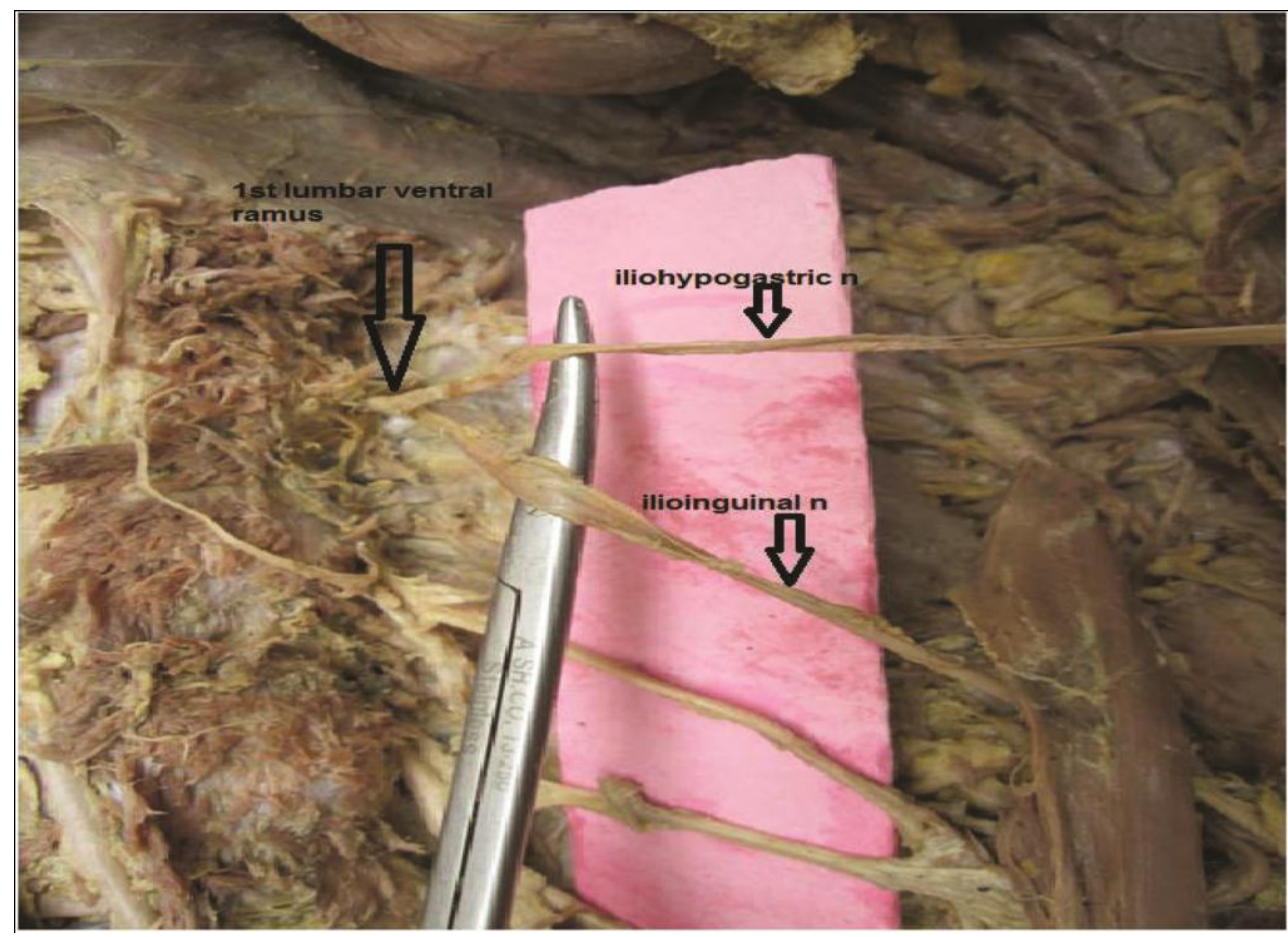

Fig. (5): Aphotograph showing the first lumbar ventral ramus divided to give the iliohypogastric and ilioinguinal nerves. 


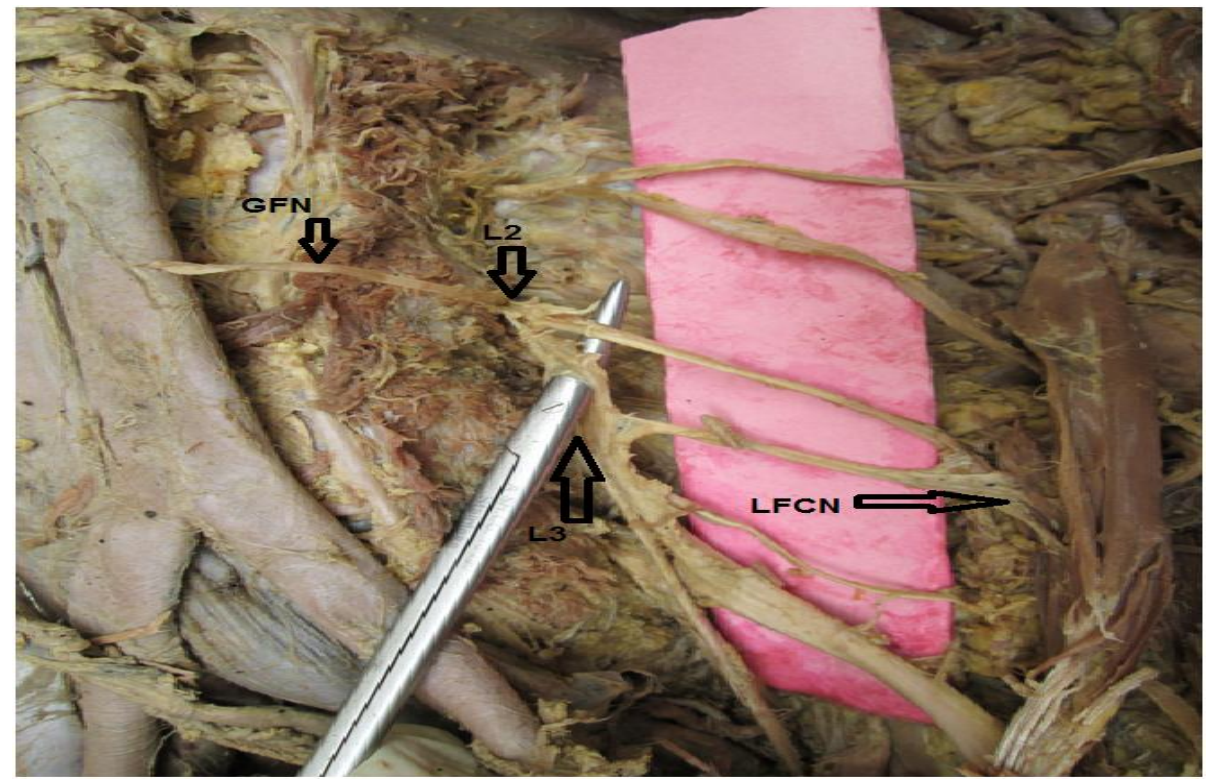

Fig. (6): Aphotograph showing the genitofemoral (GFN) and the lateral femoral cutaneous nerves (LCNT) originated from the second lumbar ventral ramus.

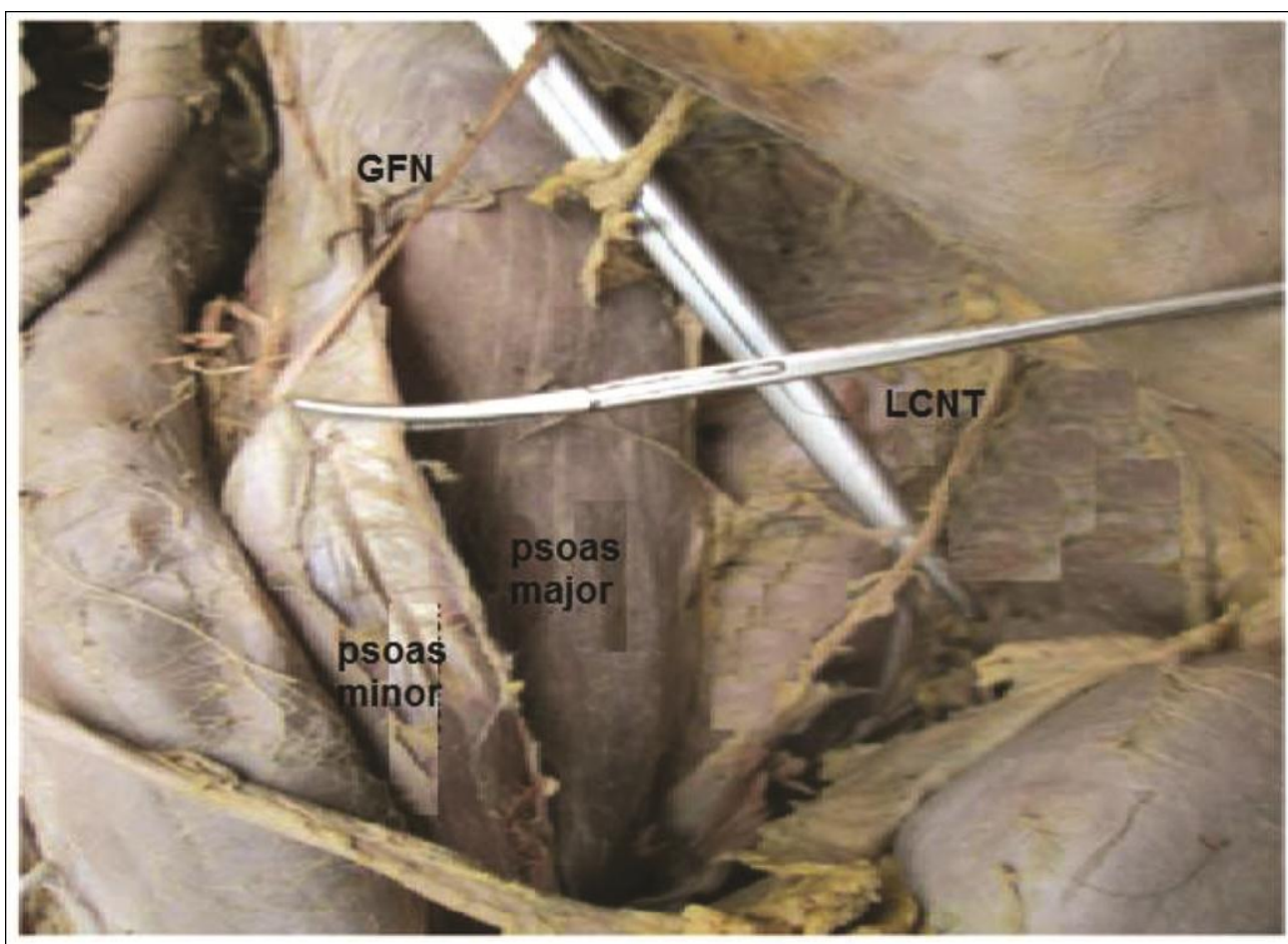

Fig. (7): Aphotograph showing the genitofemoral (GFN) descended on the ventral aspect of the psoas major muscle while the lateral femoral cutaneous nerve (LCNT) crossed the lateral border of the psoas major. 


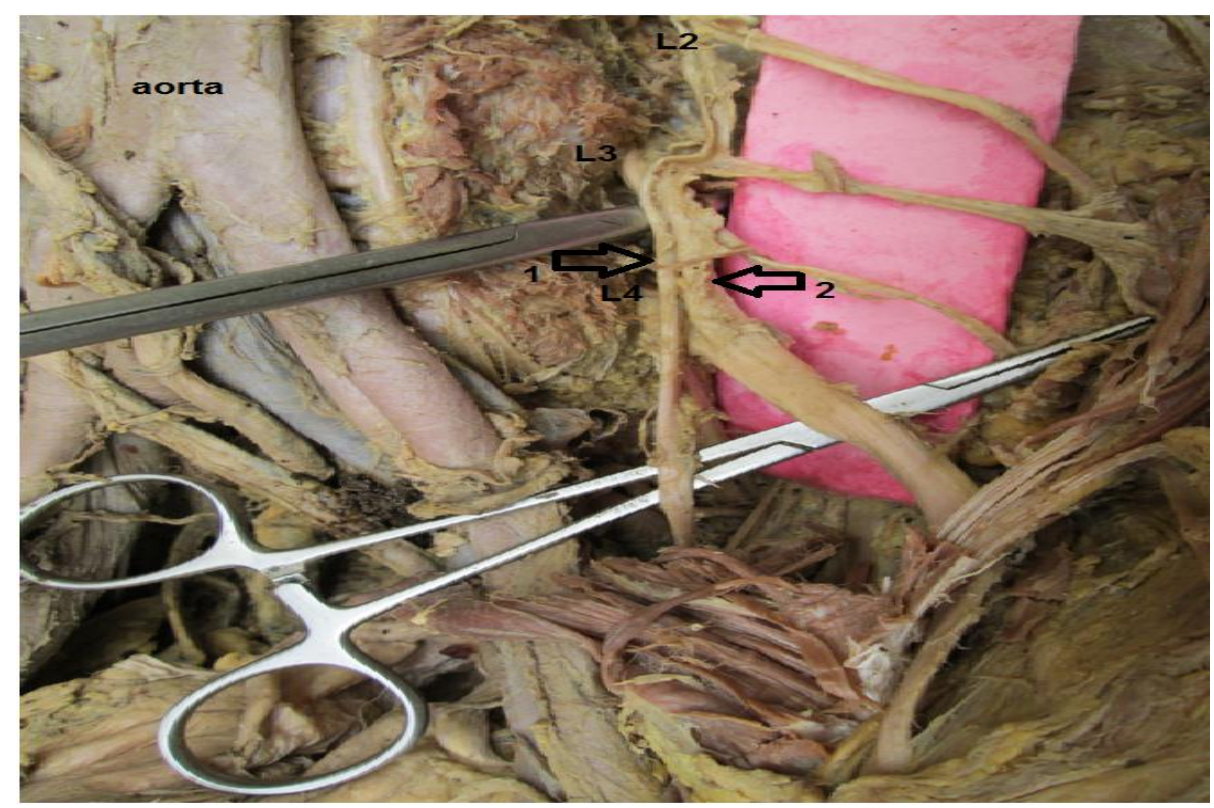

Fig. (8): Aphotograph showing the anterior divisions of L2, 3, 4 were smaller and gave rise to the obturator nerve. The large posterior divisions of the ventral rami of L2, 3, 4 united to form the femoral nerve.

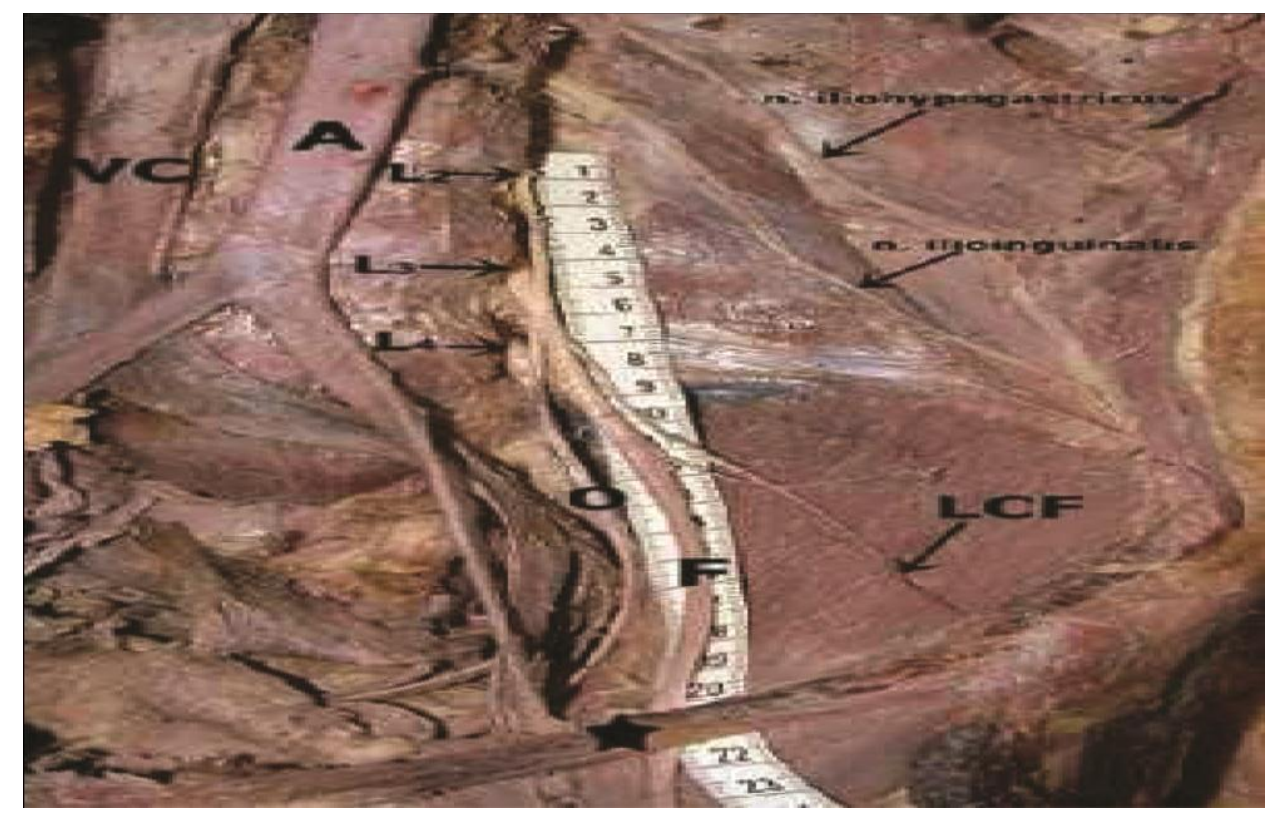

Fig. (9): Aphotograph showing anterior view of the posterior abdominal wall after the removal of the internal organs for measurement of the femoral nerve (A: Abdominal aorta, F: Femoral nerve, L2-L3-L4: The anterior ramus of the second, third and fourth lumbar spinal nerves respectively, LCF: Lateral femoral cutaneous nerve, O: Obturator nerve, VC: Inferior vena cava, asterisk: Inguinal ligament). 


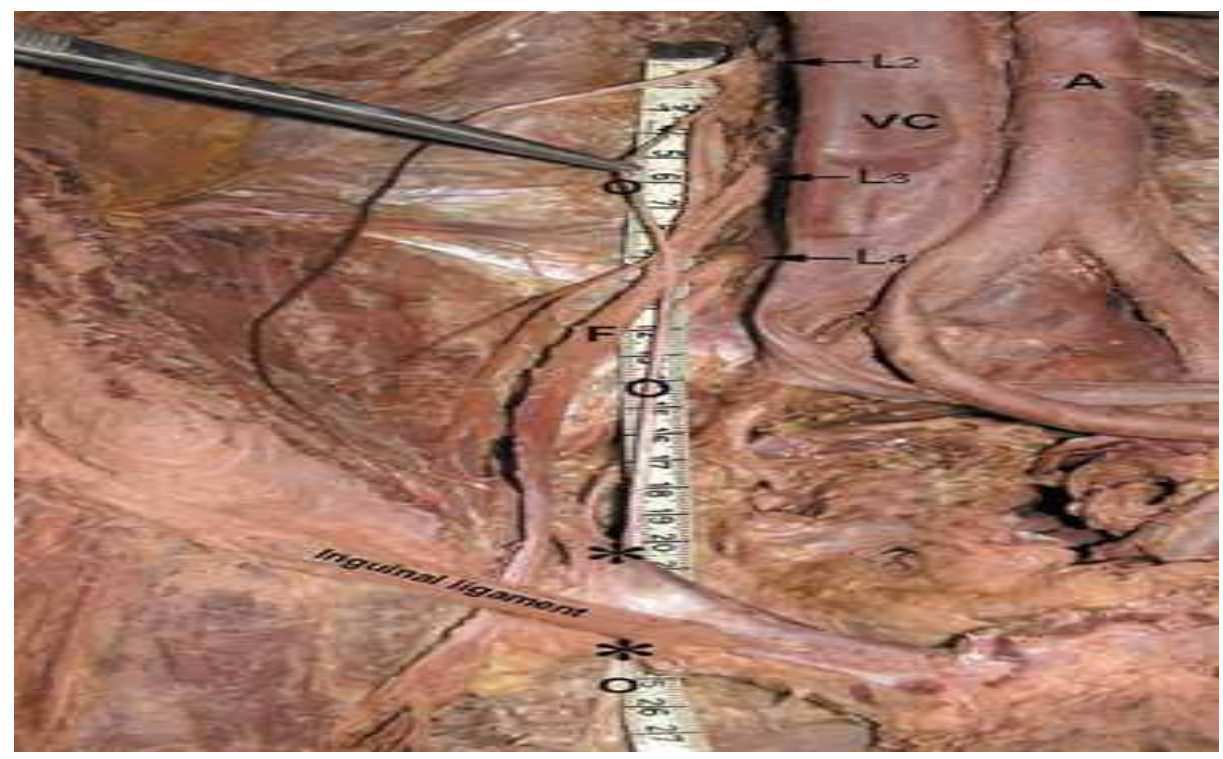

Fig. (10): Aphotograph showing anterior view of the posterior abdominal wall after the removal of the internal organs for measurement of the obturator nerve (A: Abdominal aorta, F: Femoral nerve, L2-L3-L4: The anterior ramus of the second, third and forth lumbar spinal nerves respectively, LCF: Lateral femoral cutaneous nerve, O: Obturator nerve, VC: Inferior vena cava, asterisks: obturator canal entrence and exit).

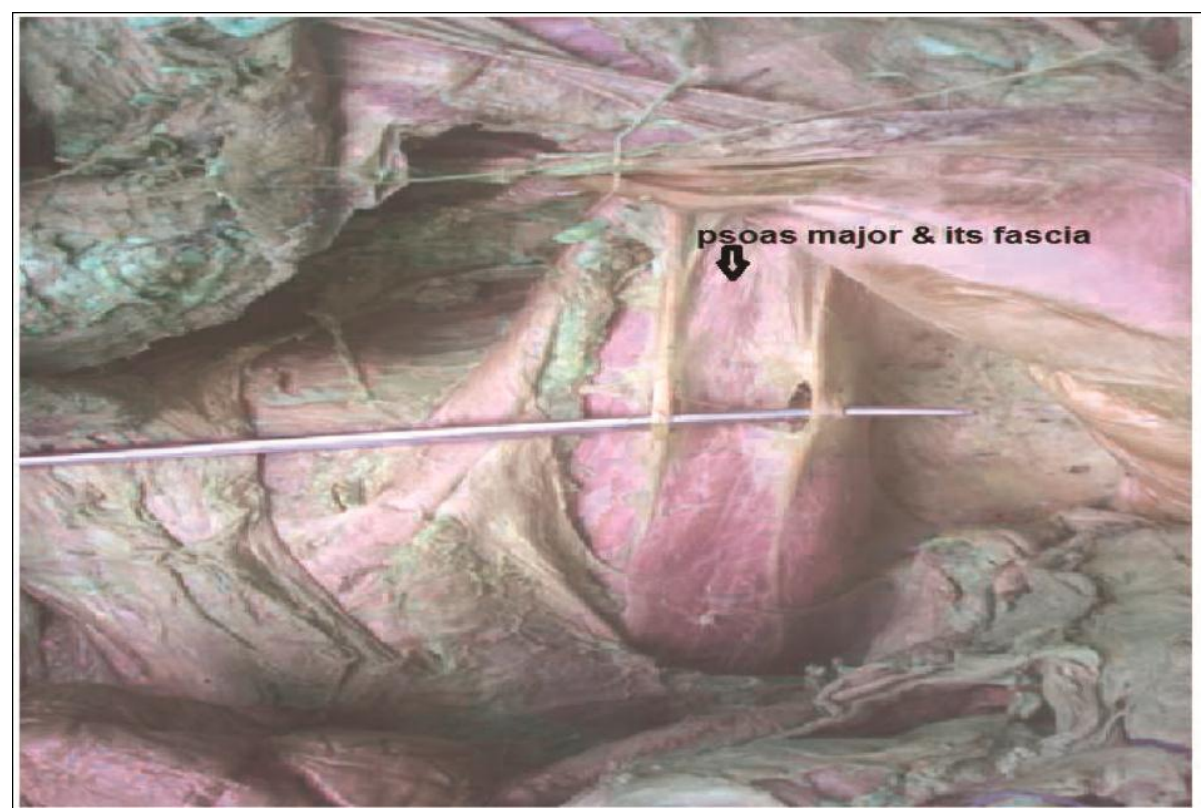

Fig. (12): Aphotograph showing the genitofemoral nerve (GFN) laying ventral to left psoas major muscle. A second branch which also laying ventral to psoas major muscle coursing parallel to this nerve. It is mostly accessory genital nerve. 


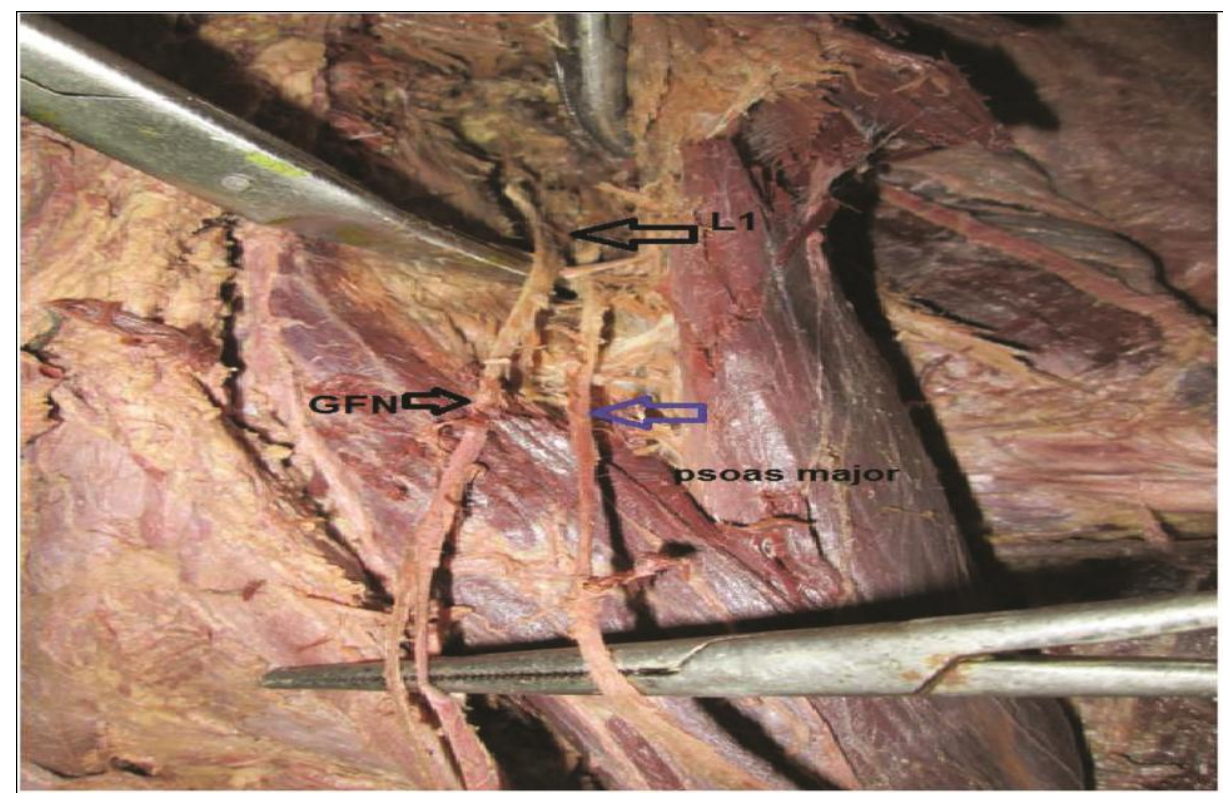

Fig. (13): Aphotograph showing dissection of psoas major showing the genitofemoral nerve (GFN) was originating from the ventral ramus of L2. The blue arrow point to another branch which was also originated from the ventral ramus of L2 was descending parallel to GF nerve. It is mostly accessory genital nerve.

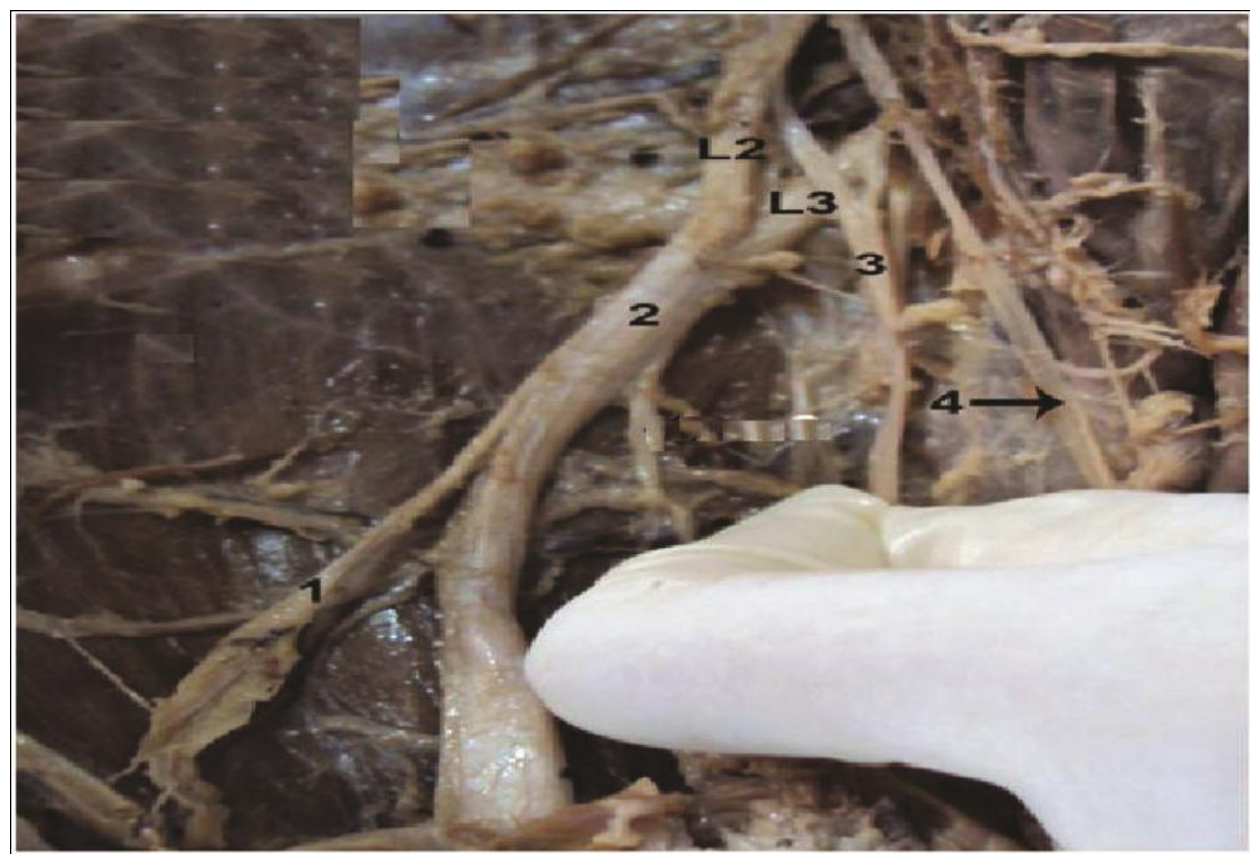

Fig. (14): Aphotograph showing right lateral cutaneus nerve of the thigh arising from femoral nerve. 1- lateral cutaneus nerve of the thigh, 2- femoral nerve, 3- obturator nerve, 4- nerve to psoas major. 


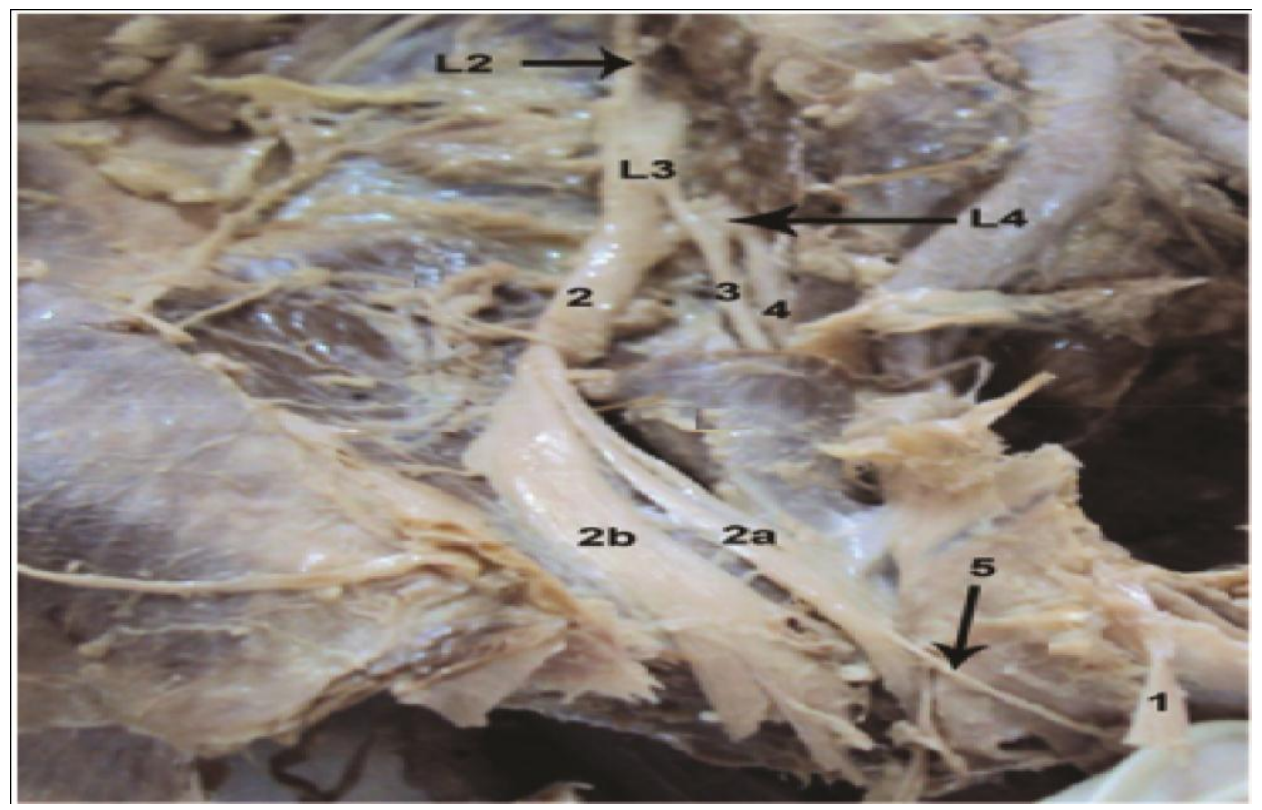

Fig. (15): Aphotograph showing early division of the right femoral nerve in iliac fossa. Nerve to pectineus arising from anterior division behind the inguinal ligament. 1inguinal ligament cut, 2- femoral nerve, 2a- anterior division of femoral nerve, 2bposterior division of femoral nerve, 3- obturator nerve, 4- lumbosacral trunk, 5- nerve to pectineus.

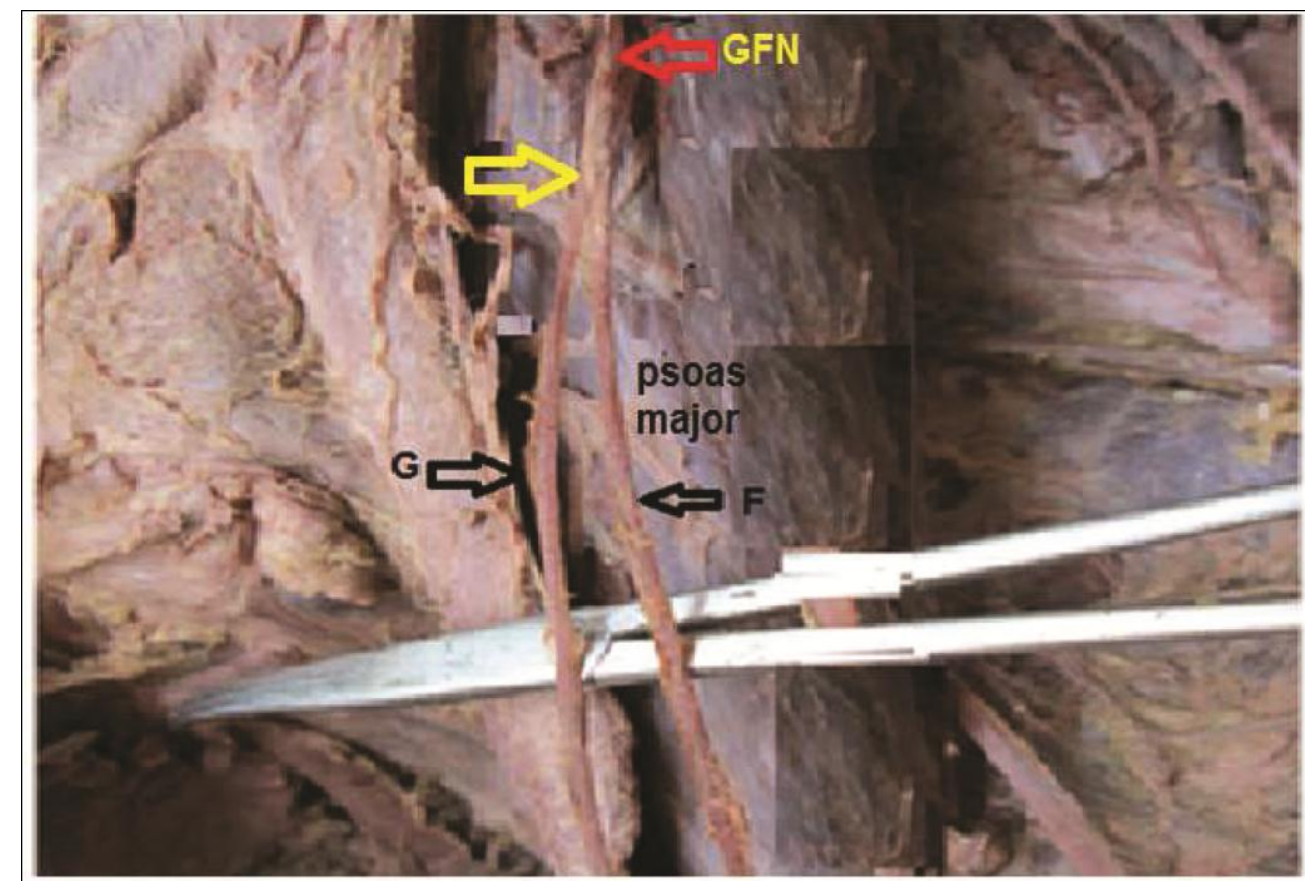

Fig. (16): Aphotograph showing the the genitofemoral nerve (GFN) has prematurely bifurcated (At the yellow arrow into two components, the genital branch $(\mathrm{G})$ and femoral branch (F). Fibers of the psoas major lie between these branches. 


\section{Discussion}

Tubbs et al., 2005 reported that the genitofemoral (GF) nerve always pierced the psoas major muscle more or less in the midline, without mentioning the details. In the present study, the nerve pierced the middle third of the psoas major in $90 \%$ at L3L4 vertebra.In $2(10 \%)$ cases, GF bifurcated into the genital and femoral branches at the upper rather than mid-portion of the anterior surface of the psoas major while several authors (Hollinshead, 1982), (Skandalakis, 2004) and (Standring et al., 2008) have described that the GF nerve sometimes divided into genital and femoral branches prior to emergence from the psoas major.

The lateral femoral cutaneous (LFC) nerve of thigh is normally a branch of the lumbar plexus. In our study we found the origin of lateral cutaneous nerve of thigh from the femoral nerve in two (10\%) of 20 lumbar plexuses while (Astrik and Dave, 2011) found that the lateral cutaneous nerve of thigh arose directly from the femoral nerve in 6 (10\%) plexuses. (Diasfilho et al., 2003) reported origin of lateral cutaneous nerve of thigh from the femoral nerve inferior to the inguinal ligament in one case in their study.

In the present study the lateral femoral cutaneous nerve(LFCN) was originated from the second lumbar ventral ramus (fig. 20) while (Sim and Webb, 2004) reported that in $22(36.7 \%)$ of 60 plexuses, the lateral femoral cutaneous nerve arose from the first two lumbar nerves; in one plexus $(1.7 \%)$, the nerve arose solely from the second lumbar ventral ramus and in 6 plexuses (10\%), it arose directly from the femoral nerve, making for a total of $48.3 \%$ variation for the lateral femoral cutaneous nerve. In the present study the lateral femoral cutaneous nerve was originated from the second lumbar ventral ramus (fig. 20) while (De Ridder et al., 1999) reported that in 24 of 200 cadavers, the lateral femoral cutaneous nerve arose from the L1 and L2 and even solely from the second or third lumbar nerve. In the present study, the nerve arose from T12, $\mathrm{L} 1$ and $\mathrm{L} 2$ in $1(5 \%)$ out of 20 lumbar plexuses.

lateral femoral cutaneous nerve may arise from the femoral nerve and this may have impact on the clinical efficacy of lumbar plexus blockade, since femoral nerve blockade is likely to produce blockade in the area of distribution of lateral cutaneous nerve of thigh in these plexuses. Similarly, lateral cutaneous nerve of thigh blocks would produce femoral nerve blockade as described by (Sharrock, 1980). The impact of the presence of this variation on femoral and lateral cutaneous nerve of thigh blockade need to be investigated.

In the present study the LFC nerve normally passes distally underneath the inguinal ligament medial to the anterior superior iliac spine. While a passage through the inguinal ligament or through a bony canal have been reported by (Carai et al., 2009).(Tubbs et al., 2005) observed that in $80.5 \%$ of cases the nerve pierced the IL 1 $\mathrm{cm}$ medial to the anterior superior iliac spine (ASIS). In the present study the LFC nerve passes deep to the inguinal ligament $3.5 \mathrm{~cm}$ medial to ASIS in all dissected cadevers to enter the thigh infront the sartorius muscle where it divides into anterior and a posterior branches. 
This disagrees with (Mattera et al., 2008) who performed an extensive study on the relationship of LFCN to the ASIS in 64 groins. They concluded that in $50 \%$ of the cases, the nerve was at a distance of 1-20 mm from the ASIS, in $35.9 \%$ the LFCN contacted the ASIS and in $14.1 \%$ the distance was moor than $20 \mathrm{~mm}$ from the ASIS. (Carai et al., 2009) in their retrospective study on the LFCN suggested that in $87 \%$ of cases the nerve was inferolateral to the ASIS.

(Moro et al., 2003) observed that the LFCN passes $4 \mathrm{~cm}$ behind the anterior superior iliac spine (ASIS) over the iliac crest. In our series, we did not find any cases with such characteristics. These variations in distance may affect the success of nerve decompression surgery for meralgia paresthetica. (Carai et al., 2009) proposed that the LFCN traversing deep to the IL in $85.2 \%$ of cases is prone to associated traction between IL anteriorly and fascia iliaca posteriorly; on the other hand, when it runs through the IL, it is liable to the compression syndrome.

Femoral nerve (FN), the largest outflow of the lumber plexus (LP), traverses deep to the IL to the thigh. In the current study, in $90 \%$ of cases, the FN is formed 5-6 $\mathrm{cm}$ inferior to the iliac crest, similar to the findings reported by (Tubbs et al., 2005). In the present study the FN passes distally underneath the inguinal ligament on the anterior surface of iliopsoas muscle lateral to the femoral artery while (Bergman et al., 2006) described a position of FN in between the femoral vessels as well as a position within the substance of iliopsoas muscle.

In the present study the obturator nerve $(\mathrm{ON})$ enters the thigh by passing through the obturator canal and divides into anterior and posterior branches which are separated at first by some of the fibers of the obturator externus and lower down by the adductor brevis. This In disagreement with (Bergman et al., 2006) who described in a case report study that both the anterior and posterior branches of the $\mathrm{ON}$ may pass posterior to the adductor brevis muscle. In the present study the $\mathrm{ON}$ arises in all cases from the ventral divisions of the second, third and fourth lumbar nerves while (Hollinshead 1982) described a very variable origin of $\mathrm{ON}$ as arising from the third and fourth lumbar nerves in $175(76.7 \%)$ of 228 plexuses.

These results are contradicted by (Bardeen and Elting, 1991) as cited by (Hollinshead 1982) who observed that the obturator nerve arising from the ventral division of L2, L3 and L4 spinal segments in all cases except where the plexus was prefixed. In the present study, the similar findings were seen. Although the $\mathrm{ON}$ is well protected by the bony pelvis and the adjoining muscles, obturator neuropathy is the most common neuropathy observed after major gynecologic surgeries or pelvic trauma.

\section{Conclusion}

The lumbar plexus is located in the substance of the psoas major muscle on the posterior abdominal wall. The posterior approach is the best way to access the entire lumbar plexus and meticulous dissection is required for the best exposure. The branches of the lumbar plexus may be injured during lumbar plexus block and certain surgical procedures, particularly in the lower abdominal region (appendectomy, inguinal hernia repair, iliac crest bone graft harvesting and gynecologic procedures through transverse 
incisions). Thus, a better knowledge of the regional anatomy and its variations is essential for preventing from the lesions of the branches of the lumbar plexus.

\section{REFERENCES}

Anloague A and Huijbregts P (2010): Anatomical Variations of the Lumbar Plexus: A Descriptive Anatomy Study with Proposed Clinical Implications. The journal of manual and manipulative therapy; 4(17): 107- 114.

Astik RB and Dave UH (2011): Anatomical variations in formation and branching pattern of the femoral nerve in iliac fossa: a study in 64 human lumbar plexuses. The journal of People's Sci Res; 4:14-9.

Bardeen CR and Elting AW (1991): A statistical study of the variations in the formation and position of the lumbo-sacral plexus in man. American Journal of Anat. Anat. Anz; 19:124- 232.

Bergman RA, Afifi AK and Miyauchi R(2006): Variations of connections between lumbar and sacral plexuses. In: Illustrated encyclopedia of human anatomic variation: Part III: Nervous System: Plexuses, University of Iowa; 3: 1-35.

Capdevila X, Coimbra C and Choquet $\mathbf{O}$ (2005): "Approaches to the lumbar plexus: success, risks, and outcome," Regional Anesthesia and Pain Medicine. 30(2):150-62.

Carai A, Fenu G and Sechi E (2009): Anatomical variability of the lateral femoral cutaneous nerve: findings from a surgical series. Clin Anat; 22:365-70.

De Ridder VA, De Lange S and Popta J (1999): Anatomical variations of the lateral femoral cutaneous nerve and the consequences for surgery. Orthop Trauma Journal; (13): 207-11.

Diasfilho LC, Valenc MM, Guimaraes FA, Medeiros RC, Silva RA, Morais MG, Valente FP and Franca SM (2003): Lateral femoral cutaneous neuralgia: an anatomical insight. Clinical Anatomy; 16 (4): 309-316.

Gandhi KR, Joshi SD and Joshi SS (2013): Lumbar plexus and its variations. Journal of the Anatomical Society of India; 62: 1-5.

Hollinshead WH (1982): Anatomy for surgeons. In: The Back and the Limbs 3rd edn. Harper and Row Publishers. Journal of Orthopedic; 3:583-8.

Mattera D, Martnez F and Soria V (2008): Surgical anatomy of the lateral femoral cutaneous nerve in the groin region. Journal of Eurobian Anatomy; 12:33-7.

Moro T, Kikuchi S, Konno S and Yaginuma H (2003): An anatomical study of the lumbar plexus with respect to retroperitoneal endoscopic surgery. Spine 28; 423-428. 
Sharrock N (1980): Inadvertent "3-in-1" block following injection of the lateral cutaneous nerve of thigh. Anesthesia and Analgesia; 59 (11): 887-888.

Sim IW and Webb T (2004): Anatomy and anaesthesia of the lumbar somatic plexus. Anaesth Intensive Care Journal; 32:178-87.

Skandalakis JE 2004. Retroperitoneum. Skandalakis Surgical Anatomy. International Student edition. Paschalidis Medical Publication, 517-72.

Standring S and Borley N (2008): Gray's anatomy. In Posterior Abdominal Wall and Retroperineum. 40th ed. London: Churchill Livingstone: 1367-8.

Tubbs RS, Salter EG and Wellons JC (2005): Anatomical landmarks for the lumbar plexus on the posterior abdominal wall. Neurosurg Spine Journal; 2:335-8.

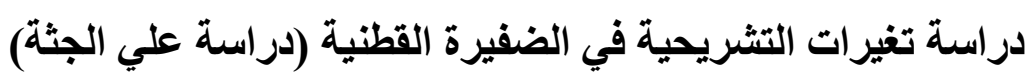

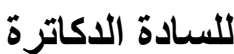

$$
\text { ' جمال احمد دسوقي ‘ ماجد الانصاري ‘ احمد كمال البناء محمد مندور }
$$

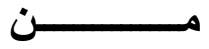

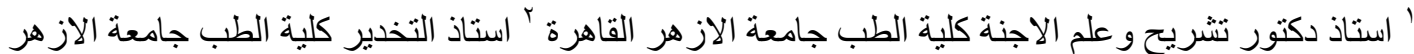

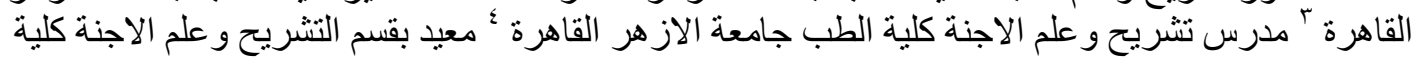
الطب جامعة الاز هر القاهرة الطازة

تقع الضفيرة القطنية في جوهر العضلة القطنية الكبرى في جدار البطن الخلفي.

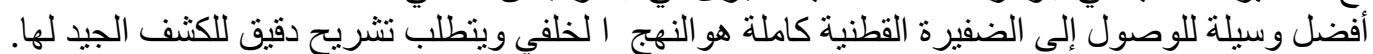

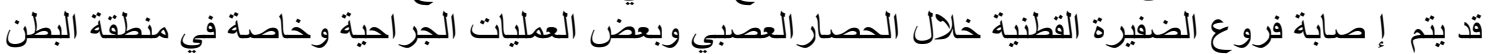

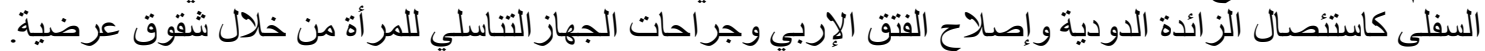

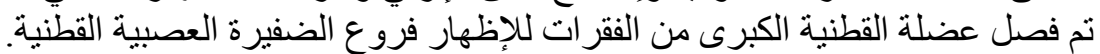

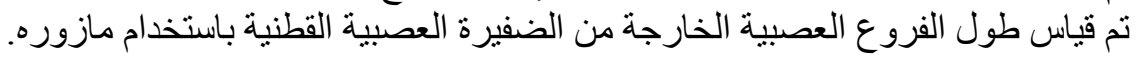

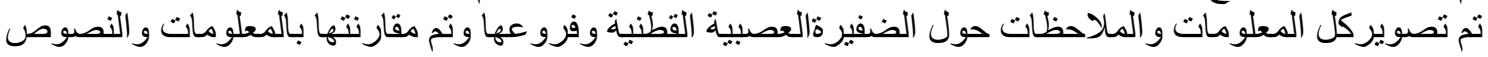
القياسية بالكتب العلمية. لوحظ أثناءالبحث وجود العرية اختلافات كثيرة فى الأعصاب الناشئة من الضفيرةالقطنية سواء من ناحية المنشأ

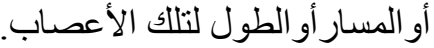
ولذلك فإن المعرفةالدقيقة للاختلافات التشريحية للضفيرةالقطنية وتبايناته أمرضروري للنع إصابة أب فرع من 